\title{
Infrared Multiphoton Dissociation of the Siderophore Enterobactin and its Fe(III) Complex. Influence of Fe(III) Binding on Dissociation Kinetics and Relative Energetics
}

\author{
Andrew D. Leslie, Rambod Daneshfar, and Dietrich A. Volmer \\ Institute for Marine Biosciences and Department of Chemistry, Dalhousie University Halifax, Nova Scotia, \\ Canada
}

\begin{abstract}
The dissociation pathways of the siderophore enterobactin and its complex with Fe(III) were examined using infrared multiphoton dissociation (IRMPD). Under experimental conditions $(\mathrm{pH}=3.5)$, both compounds' electrospray spectra exhibited exclusively singly-charged anions. The compositions of the dissociation products were characterized by accurate mass measurements using Fourier transform ion cyclotron resonance mass spectrometry (FT-ICR MS). The primary dissociation channel for both species was determined to be the loss of one serine group from the precursor molecules. To further investigate the influence of Fe(III) binding on the intramolecular interactions, dissociation kinetics and relative energetics for the loss of this serine group were determined using the focused radiation for gaseous multiphoton energytransfer (FRAGMENT) method. From the kinetic data, it was found that enterobactin was $\sim$ seven times more reactive than its Fe(III) complex over the range of laser intensities investigated. The relative activation energies, however, exhibited similar values, $\sim 7 \mathrm{kcal}$. $\mathrm{mol}^{-1}$. These results suggest that at $\mathrm{pH}=3.5, \mathrm{Fe}(\mathrm{III})$ interacts with only two of the three serine groups. The results from the present work are believed to be valuable for the characterization of novel siderophores as well as their associated metabolites and synthetic analogues. (J Am Soc Mass Spectrom 2007, 18, 632-641) (C) 2007 American Society for Mass Spectrometry
\end{abstract}

$\mathrm{I}$ ron acquisition plays an essential role in the survival of a majority of aerobic organisms. The low solubility of Fe(III) under physiological conditions $\left(\sim 10^{-18}\right.$ $\mathrm{M}$ at $\mathrm{pH}=7$ ), however, limits the amount of $\mathrm{Fe}(\mathrm{III})$ available to bacteria from the surrounding environment. This limitation is amplified by the organism's requirement for $10^{5}$ to $10^{6}$ ferric ions per bacterial cell per generation [1]. The United States Food and Drug Administration recommends a daily iron intake of 18 mg for adults [2]. Fe(III) remains soluble in humans through binding to proteins such as transferrin, lactoferrin, and ferritin, which keep Fe(III) in solution in blood, secretory fluids, and within cells, respectively [1].

Continuous demand for the limited Fe(III) has led to aggressive iron-scavenging mechanisms in bacteria. One such mechanism is the synthesis and secretion of powerful low molecular weight Fe(III)-specific chelators, termed siderophores [3]. Interestingly, in mammals, the iron-scavenging effects of siderophores are countered by the production of the siderophoresequestering protein siderocalin [4,5]. Siderophores exhibit a wide range of chemical structures including

Published online January 5, 2007

Address reprint requests to Dr. D. A. Volmer, at his current address: Medical Research Council, Human Nutrition Research, Fulbourn Road, Cambridge, CB1 9NL, UK. E-mail: Dietrich.Volmer@mrc-hnr.cam.ac.uk hydroxamates, catecholates, and $\alpha$-hydroxycarboxylates [6]. One particular catecholate Fe(III) chelator, enterobactin (ent), was shown to exhibit the highest known $\mathrm{Fe}(\mathrm{III})$ binding affinity $\left(\log K_{\mathrm{f}} \approx 49\right)$ [7].

Enterobactin was first isolated from bacteria in 1970 by two independent research groups, Pollack and Neilands from Salmonella typhimurium [8] and O'Brien and Gibson from Escherichia coli [9]. Since then, significant advances have been made in the elucidation of the mechanisms behind the bacterial recognition and transport processes involved with the acquisition of $\mathrm{Fe}(\mathrm{III})$ from the environment via enterobactin [10, 11]. A variety of methods have been employed to probe the structure and binding of Fe(III) by enterobactin (entFe(III)). X-ray crystallography [12-15] and NMR [9, 15, 16] have been used for structural characterization. UV $[9,14,17,18]$, IR $[8,9,19,20]$ spectroscopy have been used to probe both the structure of enterobactin as well as the dependence of $\mathrm{Fe}(\mathrm{III})$ binding on solution $\mathrm{pH}$. Other methods, such as cyclic voltametry $[9,14,15,19]$ and circular dichroism [14, 21, 22] were also used for the determination of redox potentials and chirality, respectively.

The cyclic enterobactin structure consists of a triester lactone of 2,3-dihydroxybenzoylserine, the building blocks of which are formed from the amide linkage of three 2,3-dihydroxybenzoic acid groups to 
three $l$-serine units (Figure 1a). Fe(III) binding in enterobactin occurs through hexadentate coordination of the metal with the catechol side chains [23]. This hexadentate coordination was found to be in a $\Delta$ configuration (right-hand propeller) [23]. Interestingly, the synthetic $\Lambda$ enantiomer from $D$-serine does not promote cell growth, indicating the role of chirality in Fe(III) regulation processes [24].

The use of X-ray crystallography for structural elucidation has been limited because of the difficulty in generating crystals of ent-Fe(III). Single crystal structures of complexes containing transition metals similar to $\mathrm{Fe}(\mathrm{III})$, for example vanadium(IV), however, have been obtained by Raymond and coworkers [14]. Comparison of these vanadium(IV) analogs' X-ray structures with that of the trilactone ring itself indicates that the trilactone ring is not significantly altered after forming the vanadium(IV) complex [14]. Another important feature observed in the X-ray data of enterobactinvanadium(IV) is the presence of intramolecular hydrogen bonding. These stabilizing hydrogen bonds exist between the amide protons and the catechol oxygen atoms, resulting in rigid planar catecholamide arms in the enterobactin-vanadium(IV) complex [14]. These observations, when extended to the Fe(III) complex, suggest that the remarkable stability of ent-Fe(III) is due to the ideal size and rigidity of the metal binding cavity created by the trilactone structure as well as the presence of stabilizing intramolecular hydrogen bonds [14].

Electrospray ionization mass spectrometry (ESI-MS) has been widely used for the characterization of metal complexes of organic, organometallic, and inorganic compounds in recent years $[25,26]$. ESI allows for the transfer of intact complexes from the condensed phase to the gas phase, which can then be analyzed using mass spectrometry. Structural information of ions produced by ESI can be obtained from tandem mass spectrometry (MS/MS) experiments. The fragmentation data can be used in the development of analytical strategies for the study of metal complexes in biological matrices. For example, Gledhill and coworkers have used ESI-MS/MS for detection and fragmentation studies of hydroxamate siderophores [27]. Spasojevic et al. performed ESI-MS to investigate the structure and

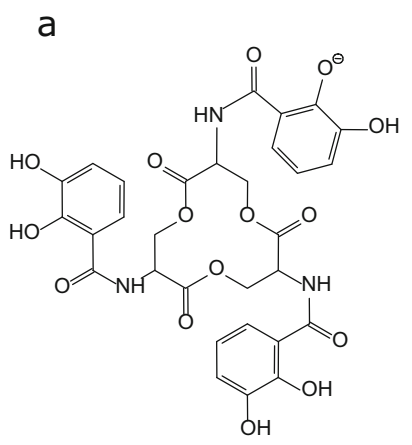

b

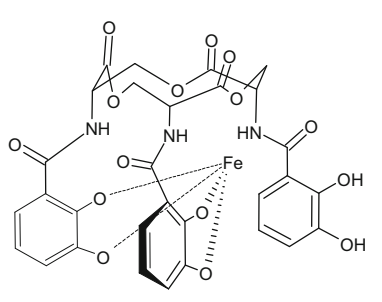

Figure 1. Structure of the (a) enterobactin and (b) enterobactinFe(III) singly-charged anions. speciation of solutions of several hydroxamate siderophores [28]. Berner et al. have reported ESI-MS/MS spectra of several iron-free catecholate siderophores including enterobactin in the positive ion mode using triple-quadrupole MS [29]. The interested reader is referred to several other interesting studies on the use of liquid chromatography-mass spectrometry (LC-MS) for efficient separation, detection, and identification of different siderophore compounds [30-33].

Although research involving enterobactin has been ongoing for nearly four decades (vide supra), to our knowledge, no detailed tandem mass spectrometry investigation of dissociation reactions of catechol-based siderophores and their iron complexes has been reported. The application of MS analysis to enterobactin is complicated by the enterobactin molecule's susceptibility to degradation. This degradation is caused by the presence of ester linkages in the enterobactin structure, subjecting the molecule to acid and base-catalyzed hydrolysis reactions in solution [19, 34]. Additionally, Raymond et al. [20] observed a $\mathrm{pH}$ dependence of the binding of $\mathrm{Fe}(\mathrm{III})$ to enterobactin. It was found that, at $\mathrm{pH}$ values $<4$, the majority of species present in solution exhibits either one or more uncoordinated side chains to the metal or even a complete dissociation of the enterobactin ligand [20]. The complex in which Fe is coordinated to all three catechol moieties, to which the exceptional $\mathrm{Fe}(\mathrm{III})$ affinity is attributed, was present only under physiological conditions.

An interesting aspect of ent-Fe(III) that has yet to be investigated is the stability of this complex compared with ent in the gas phase. Infrared multiphoton dissociation (IRMPD) has been successfully combined with mass spectrometry for the study of gas-phase ion chemistry [35], peptide and protein sequencing [36], and oligosaccharides [37]. In this technique, an ion of interest is first isolated and trapped in either a quadrupole ion trap or an ion cyclotron resonance (ICR) cell. The trapped ion is irradiated with an infrared (IR) laser, leading to the absorption of photons. This absorption of energy is stored in the form of excited vibrational modes and can lead to bond cleavages. The amount of energy absorbed by the ion depends on the laser power and the length of the irradiation period. Similarly, IRMPD can be used for the determination of the activation energy, $E_{a}$, for gas-phase unimolecular dissociation reactions. This approach was first introduced for small molecules (<50 atoms) by Dunbar [38, 39], and later extended to large biomolecules ( $>50$ atoms) by Marshall and coworkers [40, 41]. These authors renamed the technique as focused radiation for gaseous multiphoton energy-transfer (FRAGMENT).

This study represents the first comprehensive characterization of enterobactin and its complex with Fe(III) using tandem mass spectrometry. The dissociation behavior of enterobactin and its complex with Fe(III) in the negative ion mode has been investigated using IRMPD and Fourier transform-ion cyclotron resonance (FT-ICR) mass spectrometry. In addition, to study the 
effect of Fe(III) binding on the unimolecular kinetics and relative activation energies for the dissociation of enterobactin in the gas phase, time-resolved IRMPD experiments were carried out on ent and ent-Fe(III). The FRAGMENT method [40, 41]üwasüemployedüto determine relative dissociation energetics.

\section{Experimental}

\section{Materials}

Acetonitrile (Caledon, Georgetown, ON, Canada) and Milli-Q organic-free water (Millipore, Bedford, MA) were used as solvents. Ferric chloride hexahydrate and potassium hydroxide were purchased from SigmaAldrich (Mississauga, ON, Canada). GDP-D-Mannose was from EMD Biosciences (San Diego, CA). Enterobactin was obtained as an iron-free compound from EMC Microcollections GmbH (Tübingen, Germany). All materials were used without further purification.

\section{Sample Preparation}

Iron-free enterobactin was dissolved in a 1:1 solution of acetonitrile/water for a concentration of $15 \mu \mathrm{M}$. The complex of enterobactin and Fe(III) was prepared by adding ferric chloride to a solution of enterobactin in 1:1 $\mathrm{CH}_{3} \mathrm{CN} / \mathrm{H}_{2} \mathrm{O}$. The concentrations of enterobactin and ferric chloride in all experiments were $15 \mu \mathrm{M}$ and 30 $\mu \mathrm{M}$, respectively. The final $\mathrm{pH}$ of the enterobactin$\mathrm{Fe}(\mathrm{III})$ complex solution was adjusted to 3.5 using $\mathrm{KOH}$.

\section{Mass Spectrometry}

All experiments were performed on a QFT Fourier transform-ion cyclotron resonance mass spectrometer (IonSpec, Lake Forest, CA) equipped with a $9.4 \mathrm{~T}$ superconducting magnet. The sample solutions were infused directly using a Z-spray electrospray source (Waters, Milford, MA) at a flow rate of $5 \mu \mathrm{L} / \mathrm{min}$ and a needle potential of $-3.4 \mathrm{kV}$. The generated singlycharged anions of enterobactin and its Fe(III) complex were accumulated externally in a hexapole linear ion trap for a period of 1.5 and $10 \mathrm{~s}$, respectively. The accumulated ions were then transferred through an rf-only ion guide into a cylindrical ICR cell operating at room-temperature, $\sim 22{ }^{\circ} \mathrm{C}$. The typical base pressure for the instrument was $\sim 3 \times 10^{-10}$ torr. All tandem mass spectrometry (MS/MS) experiments were performed using the IRMPD technique. The MS/MS experiments were carried out by isolating the ion of interest in the ICR cell using an arbitrary waveform generator, followed by pulsed laser irradiation from a $25 \mathrm{~W}$ cw- $\mathrm{CO}_{2}$ laser $(10.6 \mu \mathrm{M}$, Synrad Inc, Mukilteo, WA) for the dissociation of the trapped ions.

Laser irradiation intensities and durations used for the FRAGMENT experiments for ent ranged from 35\% (100 to $600 \mathrm{~ms}$ ), 40\% (100 to $600 \mathrm{~ms}$ ), 45\% (87 to $300 \mathrm{~ms}$ ) and $55 \%$ (100 to $300 \mathrm{~ms}$ ). FRAGMENT experiments for
ent-Fe(III) used laser values ranging from $40 \%$ (400 to $1200 \mathrm{~ms}$ ), $55 \%$ (250 to $1200 \mathrm{~ms}$ ), 65\% (300 to $900 \mathrm{~ms}$ ), $75 \%$ (250 to $800 \mathrm{~ms}$ ), and $85 \%$ (200 to $700 \mathrm{~ms}$ ).

External and internal mass calibration was employed for accurate mass measurements and elemental formulas determinations. GDP-D-Mannose, $(\mathrm{M}-\mathrm{H})^{-}$at $\mathrm{m} / \mathrm{z}$ 604.0688, and its fragment ions were chosen for internal calibration. Mass accuracies were calculated using the MIDAS molecular formula calculator software (NHMFL, Tallahassee,iFLi[42]).ìMassïspectraüwereücquiredüusing the Ionspec Omega software, version 8.0.194. Three scans, containing $1024 \mathrm{~K}$ data points per scan, were acquired per spectrum.

\section{Results and Discussion}

The present study aims to complement and extend the existing studies on hydroxamate siderophores by providing a detailed mass spectrometric analysis of the catechol siderophore enterobactin. This analysis includes the determination of dissociation pathways as well as the investigation of ent and ent-Fe(III)'s kinetics and relative energetics in the gas-phase. Additionally, an interpretation of the study's results with respect to a comparison of condensed and gas-phase behavior will be provided at the end of this manuscript.

ShownüinüFigureü1aüisütheüstructureüofütheüfree singly-charged enterobactin anion. The deprotonation at the o-hydroxyl group allows conjugation of the ring with the carbonyl function. Due to the low solubility of $\mathrm{Fe}(\mathrm{III})$ in aqueous solutions at physiological conditions, the solutions analyzed in the present work were adjusted to a $\mathrm{pH}$ value of 3.5. The tris(catechol) form of enterobactinüsüonlyüpresentüatüpHï> $4 \dot{u}[20]$.üAtüpHü< 4 , Raymond and coworkers have shown that ent-Fe(III) is partially coordinated and can be present as a bis(cat-

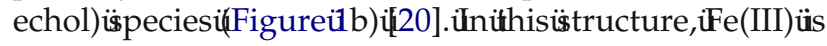
proposedütoüpreferüaütetrahedralügeometryü(Figureülb). Alternative structures with other donor moieties, e.g., serine carbonyls, occupying the vacant Fe(III) coordination sites could also be possible. These differences in coordination were investigated through discerning fragmentation pathways and measuring relative dissociation energies in the gas-phase (vide infra).

ESI of solutions containing $15 \mu \mathrm{M}$ enterobactin and $15 \mu \mathrm{M}$ enterobactin plus $30 \mu \mathrm{M} \mathrm{FeCl}$. produced exclusively singly-charged anions at $m / z 668,(\mathrm{M}-\mathrm{H})^{-}$, and $m / z$ 721, (M $+\mathrm{Fe}(\mathrm{III})-4 \mathrm{H})^{-}$, for ent and ent-Fe(III), respectivelyü(Figureư). îNoüpositiveüonsüwereübserved under the experimental conditions used in this study. For ent-Fe(III) solutions, ions resulting from dissociation of $m / z 721$ were observed at $m / z 410,454$, and 498 in the full scan spectra. These product ions were the result of in-source dissociation or degradation of the precur-

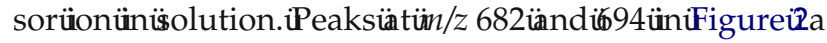
andüm/z 676üandỉ865ünüFigureỉßbüremainüunidentified and are probably due to impurities. The $\mathrm{K}^{+}$adduct of the ent-Fe(III) complex was also observed at $m / z 759$. 

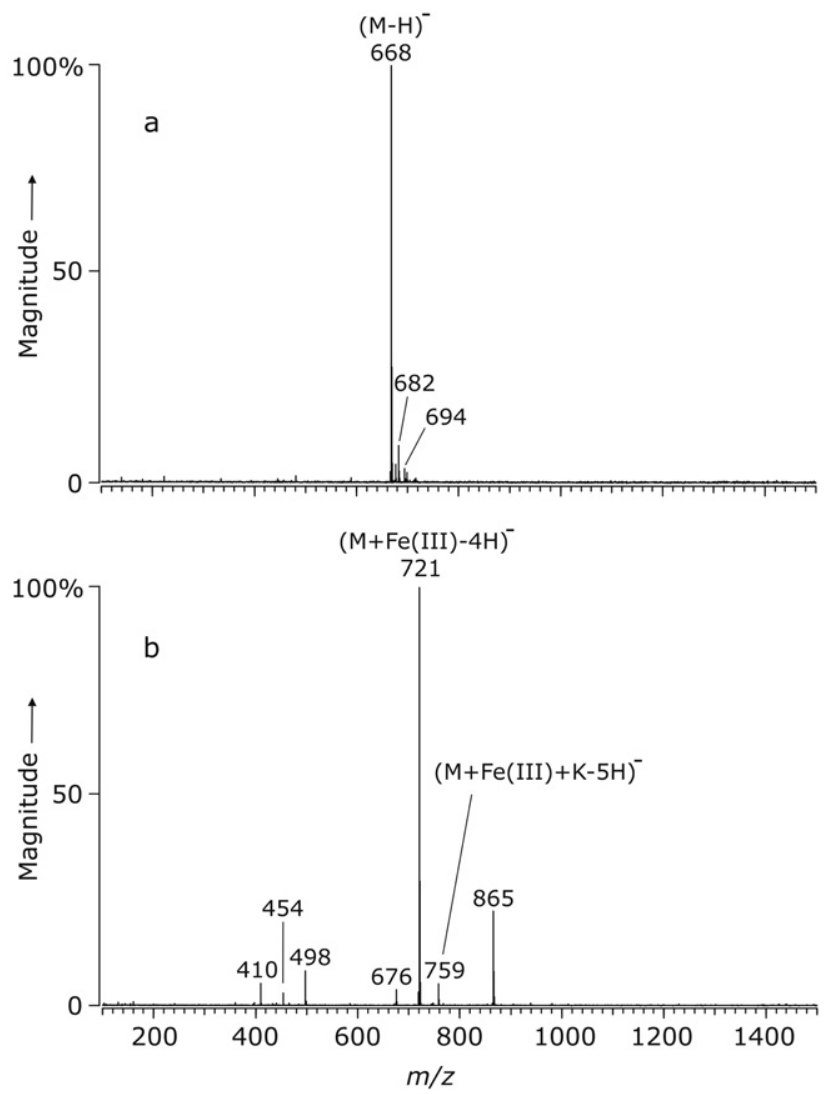

Figure 2. ESI mass spectra of $1: 1 \mathrm{H}_{2} \mathrm{O} / \mathrm{CH}_{3} \mathrm{CN}$ solutions containing $\sim 15 \mu \mathrm{M}$ of (a) enterobactin, and (b) enterobactin-Fe(III) complex. An external accumulation time of $1.5 \mathrm{~s}$ was used for enterobactin. To improve the signal-to-noise ratio for the enterobactinFe(III) complex, a longer external accumulation time of $10 \mathrm{~s}$ was employed.

\section{Dissociation Pathways}

Infrared multiphoton dissociation was performed using the $(\mathrm{M}-\mathrm{H})^{-}$and $(\mathrm{M}+\mathrm{Fe}(\mathrm{III})-4 \mathrm{H})^{-}$ions at varying laser intensities. Representative IRMPD spectra for theseüionsüareüshownüinüFigureüßbüandüFigureü4.üTo determine the elemental formulas of the observed ions, accurate mass measurements were performed using externalüandünternalümassücalibrations.üTablesülüandiฉ summarize the results of these measurements for the observed product ions of ent and ent-Fe(III). The singly-charged GDP-D-mannose anion, $m / z$ 604.0688, and its IRMPD products, $m / z$ 442.0165, 362.0502, 344.0396, 211.0008, and 150.0416 were employed as internal calibrants at various regions of the obtained mass spectra (see the Experimental section). A basic numbering scheme for the carbon and oxygen atoms in the triserine ring was used in this study for reasons of simplicityü(seeüFigureüБ).üAücompleteüandücomprehensive numbering scheme including the catecholamide armsücanibeüfoundünüreferenceu[43].

Figureü6üillustratesütheüproposedüpathwaysüforüthe dissociation of free enterobactin anion $(\mathrm{m} / \mathrm{z} 668)$. The pathway involves the initial cleavage of the $\mathrm{C}-\mathrm{O}$ bonds at $C(2)$ and $C(5)$, leading to $m / z 445$. The fragment ion at $m / z 445$ can then dissociate via three competing pathways. The first pathway involves abstraction of a proton from $\mathrm{C}(1)$ and cleavage of the $\mathrm{C}-\mathrm{O}$ bond at $\mathrm{C}(9)$

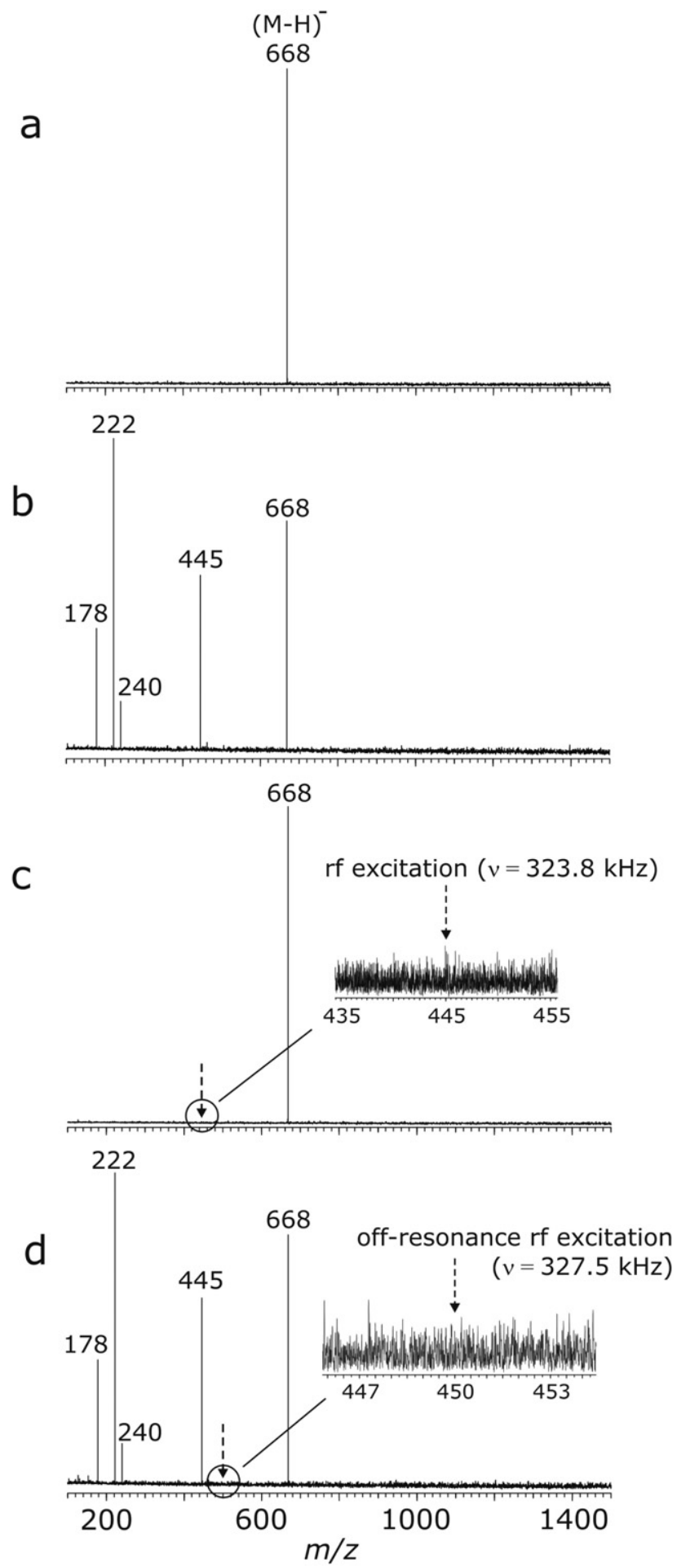

Figure 3. Mass spectra of enterobactin after (a) isolation of the singly-charged anion; (b) IRMPD of $\mathrm{m} / \mathrm{z} 668$ at $55 \%$ laser intensity for $500 \mathrm{~ms}$; (c) same as before but with a continuous rf excitation at the frequency of the $\mathrm{m} / \mathrm{z} 445$ anion $(\nu=323.8 \mathrm{kHz})$; and (d) restoration of the secondary product ions from $\mathrm{m} / \mathrm{z} 445$ by shifting the frequency of the rf excitation off-resonance from $m / z 445$ ( $\nu=$ $327.5 \mathrm{kHz})$. 


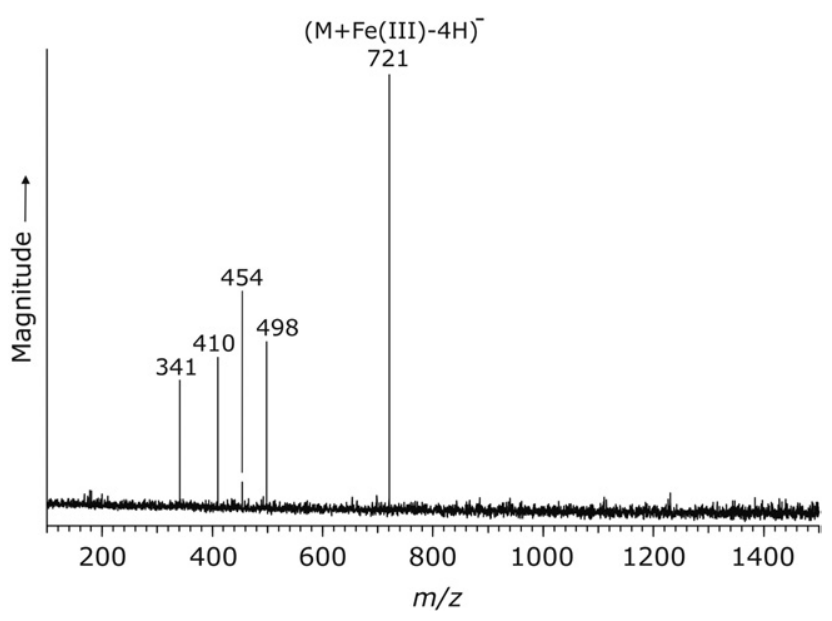

Figure 4. IRMPD mass spectrum of the singly-charged enterobactin$\mathrm{Fe}(\mathrm{III})$ anion at $75 \%$ laser intensity and $500 \mathrm{~ms}$ irradiation time.

to give $\mathrm{m} / \mathrm{z} 240$. The second pathway observed for $\mathrm{m} / \mathrm{z}$ 445 proceeds through a neutral loss of $\mathrm{C}_{10} \mathrm{H}_{9} \mathrm{NO}_{5}$ after cleavage of $\mathrm{C}-\mathrm{O}$ at $\mathrm{C}(8)$. Finally, $\mathrm{m} / \mathrm{z} 445$ can also expel two $\mathrm{CO}_{2}$ molecules as well as $\mathrm{C}_{9} \mathrm{H}_{9} \mathrm{NO}_{3}$, resulting in the product ion at $m / z$ 178. Furthermore, it was found that the ion at $m / z 240$ further fragments via loss of water to form $\mathrm{m} / \mathrm{z} 222$. This product ion in turn degrades to $\mathrm{m} / \mathrm{z}$ 178 through neutral loss of $\mathrm{CO}_{2}$.

These proposed dissociation pathways were confirmed using double-resonance experiments. In double resonance experiments, a continuous rf excitation at the frequency of the product ion of interest is used to effectively remove this ion from the cell once it is formed during the dissociation process. As a result, secondary product ions originating from this particular ion are absent in the IRMPD spectra. To verify that $\mathrm{m} / \mathrm{z}$ 445 was the only primary dissociation channel of $\mathrm{m} / \mathrm{z}$ 668 , an $\mathrm{rf}$ excitation at $m / z 445$ ion $(v=323.8 \mathrm{kHz})$ was applied throughout the laser irradiation period. All of the expected product ions of $m / z 445$; i.e., $m / z 240,222$, andï 78,üdisappearedüfromütheüIRMPDüspectraü/Figure

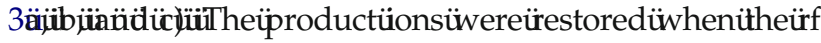
excitation frequency was shifted slightly off-resonance fromüm $/ z$ 445ü $(v=\ddot{i} 327.5 \ddot{u} k H z$,üFigureüßd).üTheseüresults clearly indicate that the disappearance of the fragment ions at $\mathrm{m} / \mathrm{z} 240,222$ and 178 are a direct result of $\mathrm{m} / \mathrm{z} 445$ dissociation rather than the ejection of ions from the ICR cell due to off-resonance excitation. As well, the

Table 1. Measured and calculated $\mathrm{m} / \mathrm{z}$ ratios, elemental formulae, and mass uncertainties for the singly-charged enterobactin anion and its IRMPD product ions

\begin{tabular}{cclcr}
\hline Nominal & Measured & $\begin{array}{c}\text { Elemental } \\
\text { formula }\end{array}$ & Calculated & $\begin{array}{r}\text { Error } \\
(\mathrm{ppm})\end{array}$ \\
\hline \hline 668 & 668.1370 & $\mathrm{C}_{30} \mathrm{H}_{26} \mathrm{~N}_{3} \mathrm{O}_{15}$ & 668.1364 & 0.9 \\
445 & 445.0878 & $\mathrm{C}_{20} \mathrm{H}_{17} \mathrm{~N}_{2} \mathrm{O}_{10}$ & 445.0883 & -1.1 \\
240 & 240.0507 & $\mathrm{C}_{10} \mathrm{H}_{10} \mathrm{NO}_{6}$ & 240.0508 & -0.4 \\
222 & 222.0400 & $\mathrm{C}_{10} \mathrm{H}_{8} \mathrm{NO}_{5}$ & 222.0403 & -0.9 \\
178 & 178.0503 & $\mathrm{C}_{9} \mathrm{H}_{8} \mathrm{NO}_{3}$ & 178.0504 & -0.6 \\
\hline
\end{tabular}

Table 2. Measured and calculated $m / z$ ratios, elemental formulae, and mass uncertainties for the singly-charged enterobactin-Fe(III) anion and its IRMPD product ions

\begin{tabular}{cclcr}
\hline Nominal & Measured & $\begin{array}{c}\text { Elemental } \\
\text { formula }\end{array}$ & Calculated & $\begin{array}{r}\text { Error } \\
\text { (ppm) }\end{array}$ \\
\hline \hline 721 & 721.0481 & $\mathrm{C}_{30} \mathrm{H}_{23} \mathrm{~N}_{3} \mathrm{O}_{15} \mathrm{Fe}$ & 721.0479 & 0.3 \\
498 & 497.9995 & $\mathrm{C}_{20} \mathrm{H}_{14} \mathrm{~N}_{2} \mathrm{O}_{10} \mathrm{Fe}$ & 497.9998 & -0.6 \\
454 & 454.0101 & $\mathrm{C}_{19} \mathrm{H}_{14} \mathrm{~N}_{2} \mathrm{O}_{8} \mathrm{Fe}$ & 454.0099 & 0.2 \\
410 & 410.0199 & $\mathrm{C}_{18} \mathrm{H}_{14} \mathrm{~N}_{2} \mathrm{O}_{6} \mathrm{Fe}$ & 410.0201 & -0.5 \\
341 & 340.9984 & $\mathrm{C}_{15} \mathrm{H}_{11} \mathrm{NO}_{5} \mathrm{Fe}$ & 340.9987 & -0.9 \\
\hline
\end{tabular}

links in the fragmentation schemes for each of the pathwaysühownüniFigureiø̈̈̈wereürerifiedibyüepetition of the double resonance process.

The dissociation behavior of ent-Fe(III) $(\mathrm{m} / \mathrm{z}$ 721) wasünvestigatedünüä̈similarifashionḯ(Figureü̈).iShown iniFigureiðüsüaüsummaryüofütheüproposedüdissociation reactions. The dissociation of the Fe(III) complex proceeds via the cleavage of two $\mathrm{C}-\mathrm{O}$ bonds at $\mathrm{C}(2)-\mathrm{O}(2)$ and $\mathrm{C}(5)-\mathrm{O}(4)$, resulting in loss of $\mathrm{C}_{10} \mathrm{H}_{9} \mathrm{NO}_{5}$, to form $m / z 498$. This product ion can in turn lose either one or two molecules of $\mathrm{CO}_{2}$, leading to $\mathrm{m} / \mathrm{z} 454$ and $\mathrm{m} / \mathrm{z} 410$, respectively. The ion at $\mathrm{m} / \mathrm{z} 454$ can also expel a molecule of $\mathrm{CO}_{2}$, giving $\mathrm{m} / \mathrm{z} 410$ or proceed through an interestingü̈lternateüreactionitoün/z 341ü̈Figureüt).üThis alternate reaction involves an initial rearrangement of $\mathrm{m} / \mathrm{z} 454$, resulting in a structure containing an isocyanate group. This species then degrades to $m / z 341$ via loss of $\mathrm{C}_{3} \mathrm{H}_{3} \mathrm{NO}$ and $\mathrm{CO}_{2}$. As for ent, performing double resonance experiments established the links in the dissociation pathways for ent-Fe(III) (data not shown).

\section{Dissociation Kinetics and Relative Energetics}

The release of iron from the aqueous ent-Fe(III) complex proceeds through hydrolysis of the ester bonds of theütriserineüringübyüaücytoplasmicüesteraseü[43].üIn activity experiments involving the cytoplasmic esterase, it was found that the enzyme was four times more active for the hydrolysis of free enterobactin as comparedüwithütheiFe(III) icomplexi[44].üAsülescribedï̈bove, iniFiguresïbüandīitheünitialüstepünitheüdissociationüof<smiles>[R]C1=C([R])C(=O)OCC([R])C(=O)OCC([R])C(=O)OC1</smiles><smiles>[R]C(COC(=O)C([R])COC(=O)C([R])COC(=O)C([R])C(=O)O)C(=O)O</smiles>

Figure 5. Simplified numbering scheme for carbons of the enterobactin triserine ring (left) and for the associated oxygens (right). $\mathrm{R}$ represents the catecholamide side chains. 


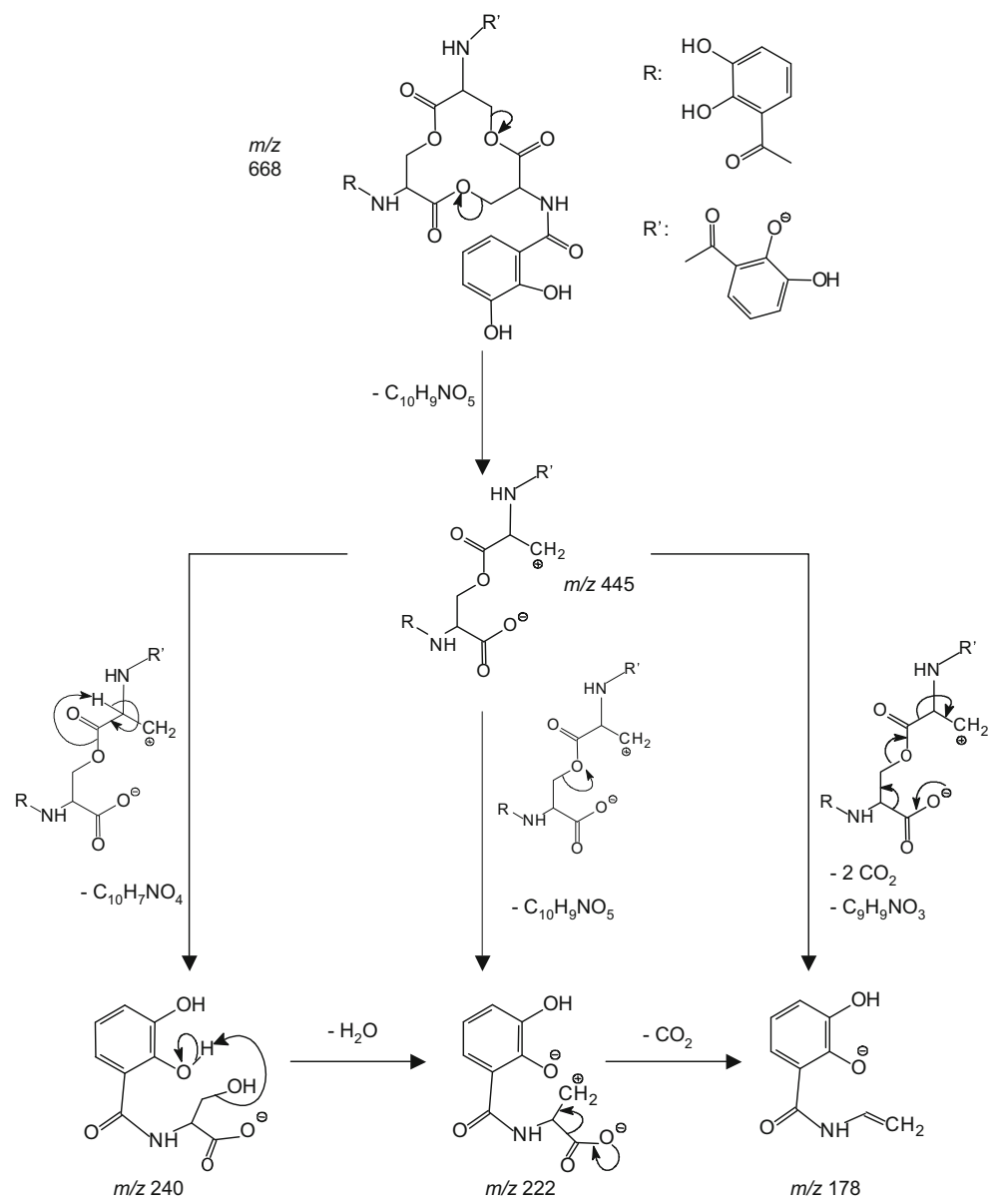

Figure 6. Proposed dissociation pathways for the singly-charged enterobactin anion.

gaseous ent and ent-Fe(III) involves cleavages in the triserine ring, which closely resemble those observed in aqueous hydrolysis reactions. It was also seen that an increase in laser intensity was required to generate a similar yield of dissociation for ent-Fe(III) compared with the free enterobactin (ent). To characterize possible stabilizing effect(s) of $\mathrm{Fe}(\mathrm{III})$ binding on intramolecular interactions of enterobactin, dissociation kinetics and relative energies for the dissociation of the triserine backbone of enterobactin and its complex with Fe(III) were determined in the gas phase.

The determination of activation parameters, activation energy $\left(E_{a}\right)$ and pre-exponential factor $(A)$, has previously been accomplished using the blackbody infrared dissociation (BIRD) technique in FT-ICR MS instrumentsü [45-i47].üInüBIRD, üionsütrappedüinüa heated ICR cell are equilibrated to a defined internal temperature through the absorption and emission of infrared photons. In the case of large ions, such as peptides and proteins, the rate of unimolecular dissociation of the activated ions is slower than the rate of photon exchange between the ion and its surroundings. As a result, at a given temperature, the internal energy of the ions can be described by a Boltzmann distribution. Under these conditions, ions are said to be in the rapid exchange limit (REX). For small ions, the rate of dissociation increases, causing depletion in the high-energy component of the Boltzmann distribution (truncated Boltzmann distribution). This leads to lower measured $E_{a}$ values than for those molecules in the REX.

A major limitation of the BIRD technique is that ions dissociating at temperatures higher than the upper temperature of the instrument can not be studied. Also, long time periods are required to reach temperature equilibrium in the ICR cell. As an alternative method, Dunbarüandücoworkersü[38, ̈̈39] üproposedüusingüaücw$\mathrm{CO}_{2}$ infrared laser for thermally activating ions without the need to heat the ICR cell and its surrounding vacuum chamber. A limitation to this technique is the difficulty of determining accurate equilibrium temperatures in the ICR cell. This precludes the determination of the pre-exponential factor as well as the calculation of absolute energy values. Despite these limitations, relative dissociation energetics have been calculated in comparativeüstudiesư 48].üToüdetermineürelativeüactivation energies $\left(E_{a, r}\right)$, Marshall and coworkers developed [40,ü11]ütheüfocusedüradiationüforügaseousümultiphoton energy-transfer (FRAGMENT) method, in which $E_{a, r}$ is determined from unimolecular dissociation reaction rate constants at various laser intensities. 


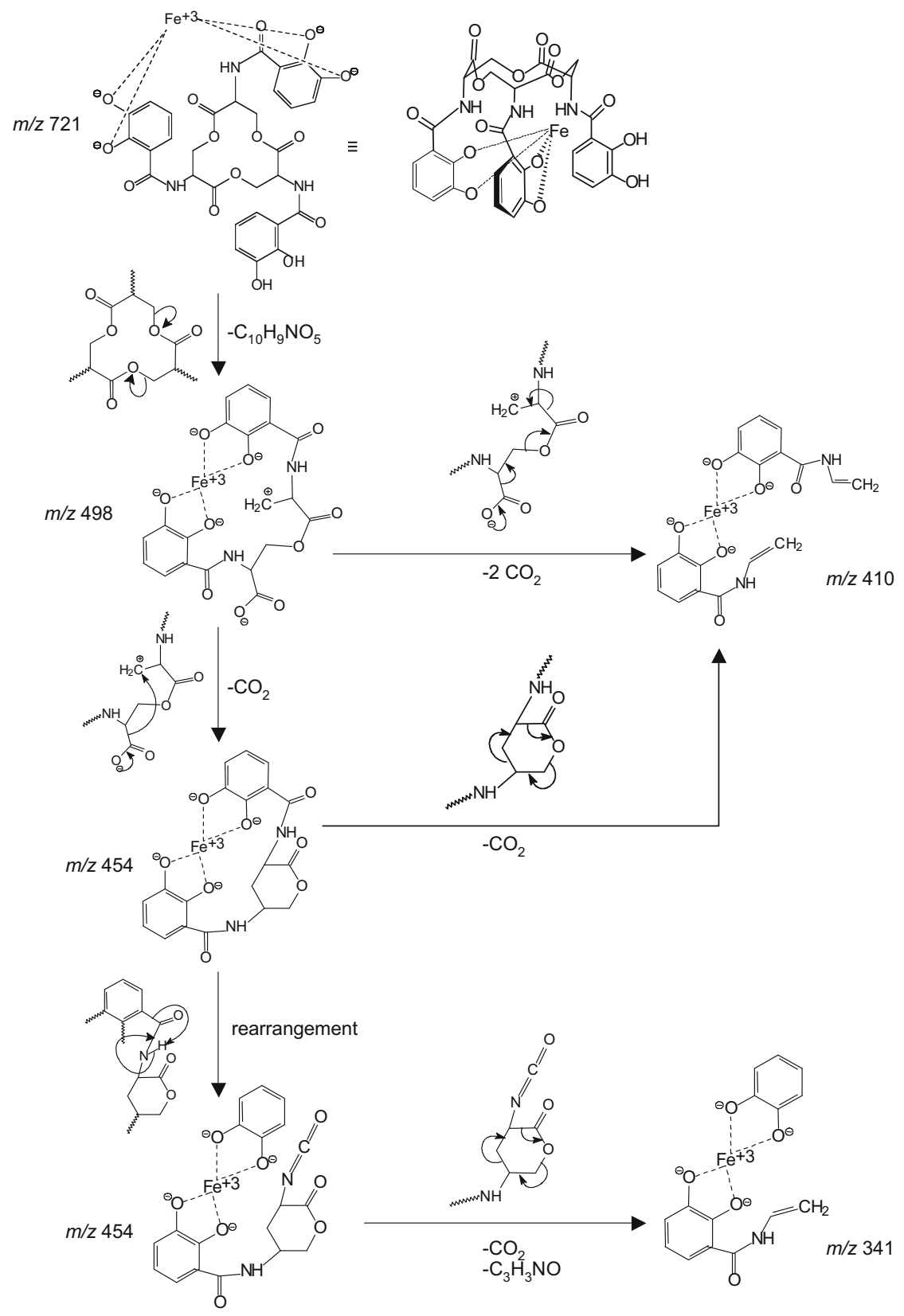

Figure 7. Proposed dissociation pathways for the singly-charged enterobactin-Fe(III) anion.

In the FRAGMENT method, the activation energy is determinedüfromitheüfollowingüequationi[38]:

$$
E_{a}=-\frac{d \ln k_{d i s s}}{d\left(\frac{1}{(k T)}\right)}=q h v\left(\frac{d \ln k_{d i s s}}{d \ln I_{\text {laser }}}\right)
$$

where $k_{\text {diss }}$ is the first-order dissociation rate constant, $q$ is the vibrational partition function for the vibrational mode that absorbs the incident IR radiation, $h$ is Planck's constant, $v$ is the frequency of radiation (10.6 $\mu \mathrm{M})$, and $I_{\text {laser }}$ is the intensity of laser radiation. Mar-

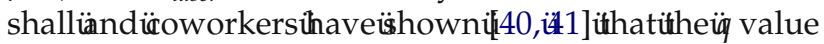

varies between 1.01 and 1.1 over the temperature range 300 to $500 \mathrm{~K}$, with an average value of 1.05 .

In the present study, dissociation kinetics and relative activation energies for the gas-phase unimolecular dissociation of ent and ent-Fe(III) were determined using the FRAGMENT method. An averaged $q$ value of 1.05 was used in our activation energy measurements. It should be emphasized that for these small molecules, the measured energy values represent an underestimation of the true value. Despite their approximation, these values are still valid for a comparative study.

The $k_{\text {diss }}$ value at each laser intensity was determined from the change in the natural logarithm of the normalized reactant ion abundance $\left(I_{R, n o r m}\right)$ with the irradia- 

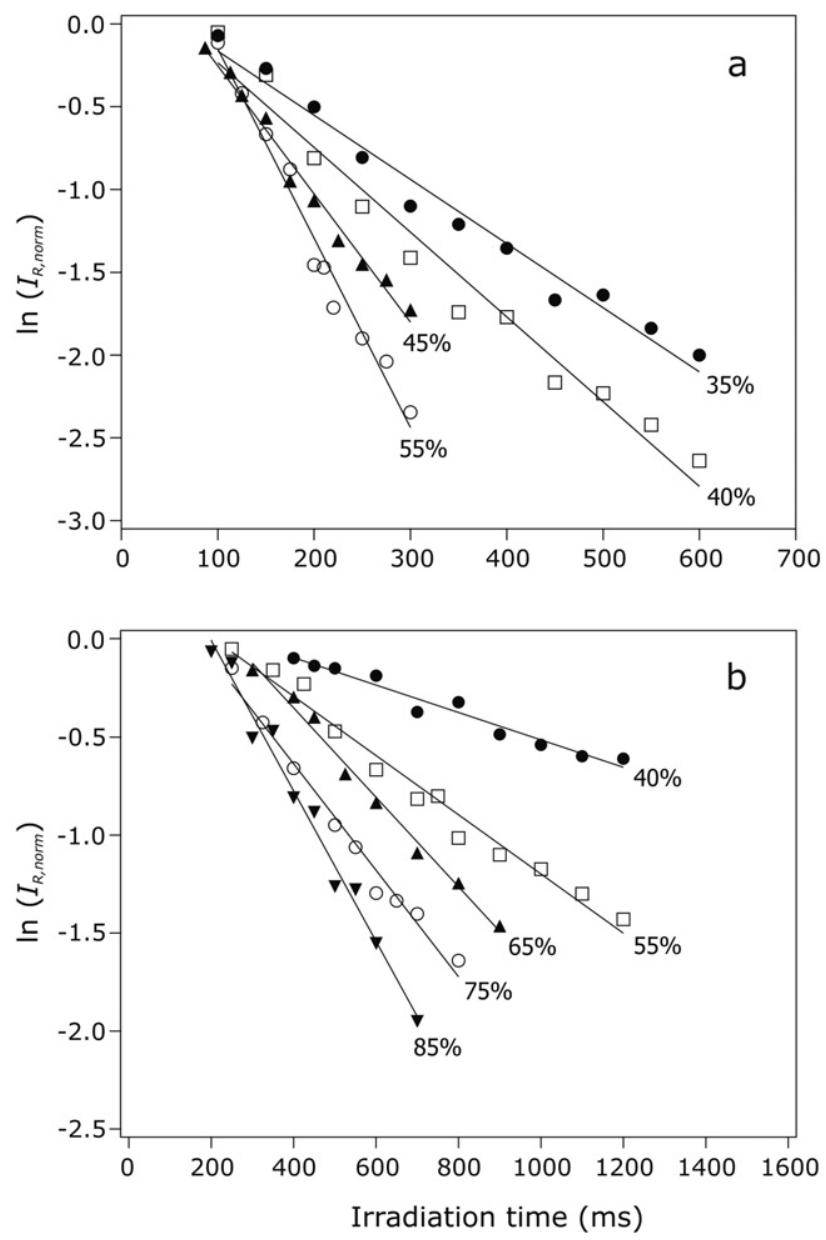

Figure 8. Dissociation kinetic data for the singly-charged anions of (a) enterobactin and (b) enterobactin-Fe(III), obtained at the laser intensities indicated.

tion time $\left(t_{\text {irr }}\right)$ using linear least-squares analysis (eq 2). $I_{R, n o r m}$ was calculated using eq 3 :

$$
\begin{aligned}
& \ln \left(I_{R, \text { norm }}\right)=-K_{\text {diss }} t_{\text {irr }} \\
& I_{R, \text { norm }}=\frac{I_{R}}{I_{R}+\sum I_{P}}
\end{aligned}
$$

where $I_{R}$ is the abundance of the reactant ion (precursor ion) and $\Sigma_{p}$ is the abundance of the product ions, including those resulting from secondary fragmentation channels. Peaks with the highest abundance in the isotopic distribution were used in all calculations in the present work.

Illustrative kinetic plots for the ent and ent-Fe(III) species at different laser intensities are shown in Figurei8.iCloseünspectionüfiFigurei8ürevealsithat, ̈̈ver the laser intensity range investigated, the rate constants for the loss of the serine group from ent is faster as compared with ent-Fe(III) at corresponding laser intensities. For example, at $40 \%$ and $55 \%$ laser intensities, loss of a single serine group was $\sim$ seven times faster for ent than for ent-Fe(III). We rationalize this observation based on the availability of three free serine groups for ent compared with only one free serine group in ent-Fe(III). This difference in free serine group availability then results in the higher apparent $k_{\text {diss }}$ for ent compared with ent-Fe(III).

In the next experiment, the influence of $\mathrm{Fe}(\mathrm{III})$ binding on the dissociation energy was investigated by comparing the measured activation energies for the loss of one serine group from ent and ent-Fe(III). $E_{a, r}$ values were determined from the slope of plots of the natural $\log$ of $k_{\text {diss }}$ versus the natural $\log$ of the laser intensity (Figureï).üTheüdeterminedüdissociationü $E_{a, r}$ was equal for both species within experimental error, with calculated values of $7.0 \mathrm{kcal} \cdot \mathrm{mol}^{-1} \pm 0.6$ for ent and 6.3 $\mathrm{kcal} \cdot \mathrm{mol}^{-1} \pm 0.3$ for ent-Fe(III). This similarity of $E_{a, r}$ values can be explained by considering the identical bond cleavages of $\mathrm{C}(2)-\mathrm{O}(2)$ and $\mathrm{C}(5)-\mathrm{O}(4)$ of the triserine ring backbone for both ent and ent-Fe(III) anions. Furthermore, it suggests that, in agreement with the proposed structure of ent-Fe(III) in aqueous solutionïttüpHü 4 4[1[20], iESI-generatedüonsümostulikelyüretain their structure as bis(catechol) in the gas phase. This leaves one serine group available for a neutral loss reaction from the ent-Fe(III) anion after ion activation by IRMPD. We are currently investigating different protocols for measuring enterobactin in aqueous solution at higher $\mathrm{pH}$ values, where the reduced $\mathrm{Fe}(\mathrm{III})$ solubility limits the application of our current experimental approach. In future studies, it will be interesting to explore the relation between the structure of the ent-Fe(III) complex and its mediating role in bacterial iron acquisition by performing tandem MS experiments under physiological conditions.

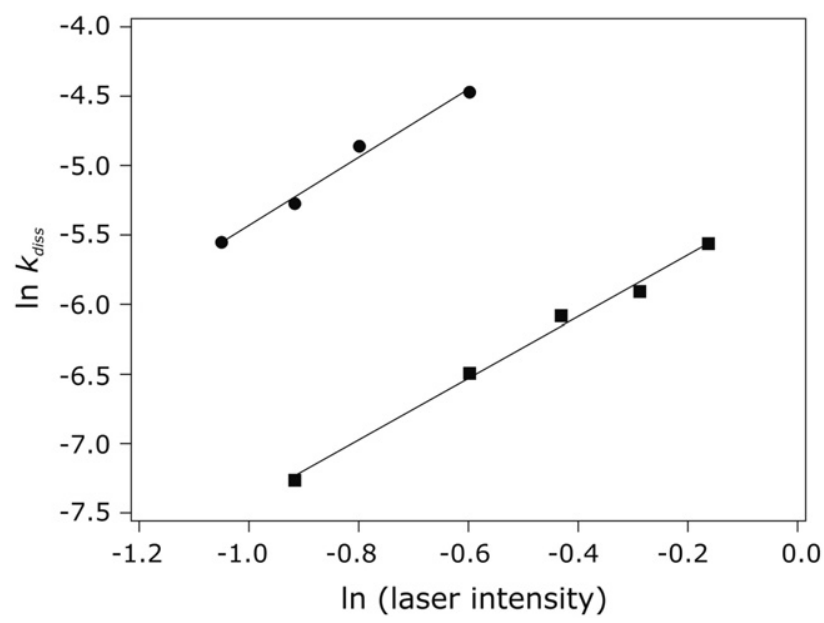

Figure 9. $\ln k_{\text {diss }}$ versus $\ln$ (laser intensity) plots for the loss of a serine group from the singly-charged anions of enterobactin (filled circle), and enterobactin-Fe(III) (filled square). 


\section{Conclusions}

The present work describes the application of infrared multiphoton dissociation for the structural elucidation of dissociation products of enterobactin and its complex with $\mathrm{Fe}(\mathrm{III})$. To determine dissociation pathways and product ion structures, tandem MS experiments and accurate mass measurements were carried out on the singly-charged anions of both species using ESI-FTICR-MS. It was shown that at $\mathrm{pH}=3.5$, the primary dissociation pathway for both species involves cleavages of the triserine ring, resulting in the loss of one serine group from the precursor ion.

The dissociation kinetics and relative energetics for the loss of this serine group were measured using the FRAGMENT method. The kinetic data clearly indicate the strong influence of $\mathrm{Fe}(\mathrm{III})$ binding on reactivity. Faster dissociation rates were observed for ent compared with ent-Fe(III) at corresponding laser intensities. The measured $E_{a, r}$ values for the loss of serine, however, were found to be very similar at $\sim 7 \mathrm{kcal} \cdot \mathrm{mol}^{-1}$. These results suggest that the interaction between $\mathrm{Fe}(\mathrm{III})$ and enterobactin is limited to two of the three catechol side chains and does not appear to influence the dissociation energy of the triserine ring for the loss of one serine subunit.

The acquisition of iron from the local environment via siderophores plays a critical role in the survival of aerobic microorganisms. As such, siderophores remain of high interest as they give valuable insight into iron regulation, transportation, and storage processes. Furthermore, the ability of siderophores to deliver iron to the bacterial cell can be exploited for the development of new antibiotics, making use of this mode of entry into the cell. The identified product ions and dissociation pathways presented here could prove valuable in the characterization of novel siderophores as well as their associated metabolites. Furthermore, the FRAGMENT method allowed for the facile determination of dissociation kinetics and relative energetics for the study of the intramolecular interactions in the gas phase.

\section{Acknowledgments}

DAV acknowledges support from the Natural Sciences and Engineering Research Council of Canada (NSERC, Discovery Grant "Experimental studies of biological coordination chemistry using advanced analytical mass spectrometry techniques").

\section{References}

1. Braun, V.; Killmann, H. Bacterial Solutions to the Iron-Supply Problem. Trends Biochem. Sci. 1999, 24, 104-109.

2. Dietary Guidelines for Americans 2005. U.S. Department of Health and Human Services/U.S. Department of Agriculture: Washington, D.C. 2005; p 22.

3. Drechsel, H.; Jung, G. Peptide Siderophores. J. Pept. Sci. 1998, 4, 147-181.

4. Goetz, D. H.; Holmes, M. A.; Borregaard, N.; Bluhm, M. E.; Raymond, K. N.; Strong, R. K. The Neutrophil Lipocalin NGAL is a Bacteriostatic Agent that Interferes with Siderophore-Mediated Iron Acquisition. Mol. Cells 2002, 10, 1033-1043.

5. Abergel, R. J.; Moore, E. G.; Strong, R. K.; Raymond, K. N. Microbial Evasion of the Immune System: Structural Modifications of Enterobac- tin Impair Siderocalin Recognition. J. Am. Chem. Soc. 2006, 128, 10998-10999.

6. Drechsel, H.; Winkelmann, G. In Transition Metals in Microbial Metabolism; Winkelmann, G.; Carrano, C. J., Eds.; Harwood Academic: Amsterdam, The Netherlands 1997; pp 1-49.

7. Loomis, L. D.; Raymond, K. N. Solution Equilibria of Enterobactin and Metal-Enterobactin Complexes. Inorg. Chem 1991, 30, 906-911.

8. Pollack, J. R.; Neilands, J. B. Enterobactin, an Iron Transport Compound. Biochem. Biophys. Res. Commun. 1970, 38, 989-992.

9. O'Brien, G.; Gibson, F. The Structure of Enterobactin and Related 2,3-Dihydroxy-N-Benzoylserine Conjugates from Escherichia coli. Biochim. Biophys. Acta 1970, 215,393-402.

10. Thulasiraman, P.; Newton, S. M. C.; Xu, J.; Raymond, K. N.; Mai, C.; Hall, A.; Montague, M. A.; Klebba, P. E. Selectivity of Ferric Enterobactin Binding and Cooperativity of Transport in Gram-Negative Bacteria. J. Bacteriol. 1998, 180, 6689-6696.

11. Annamalai, R.; Jin, B.; Cao, Z.; Newton, S. M. C.; Klebba, P. E. Recognition of Ferric Catecholates by FepA. J. Bacteriol. 2004, 186, 3578-3589.

12. Anderson, B. F.; Buckingham, D. A.; Robertson, G. B.; Webb, J.; Murray K. S.; Clark, D. E. Models for the Bacterial Iron-Transport Chelate Enterochelin. Nature 1976, 262, 722-724.

13. Stack, T. D. P.; Karpishin, T. B.; Raymond, K. N. Structural and Spectroscopic Characterization of Chiral Ferric Tris-Catecholamides: Unraveling the Design of Enterobactin. J. Am. Chem. Soc. 1992, 114 1512-1514.

14. Karpishin, T. B.; Dewey, T. M.; Raymond, K. N. The Vanadium(IV) Enterobactin Complex: Structural, Spectroscopic, and Electrochemical Characterization. J. Am. Chem. Soc. 1993, 115, 1842-1851.

15. Hou, Z.; Stack, T. D. P.; Sunderland, C. J.; Raymond, K. N. Enhanced Iron(III) Chelation Through Ligand Predisposition: Synthesis, Structures, and Stability of Tris-Catecholate Enterobactin Analogs. Inorg. Chim. Acta 1997, 263, 341-355.

16. Tse, B.; Kishi, Y. Conformationally Rigid Tricyclic Tripods: Synthesis and Application to Preparation of Enterobactin Analogs. J. Org. Chem. 1994, 59, 7807-7814.

17. Hider, R. C.; Mohd-Nor, A. R.; Silver, J. Coordination of Calcium by Iron Enterobactin. Inorg. Chem. 1982, 17, 205-213.

18. Dhungana, S.; Heggemann, S.; Heinisch, L.; Möllmann, U.; Boukhalfa, H. Crumbliss, A. Fe(III) Coordination Properties of Two New SaccharideBased Enterobactin Analogues: Methyl 2,3,4-Tris-O-\{N-[2,3-di(hydroxyl) benzoyl-glycyl]-aminopropyl\}- $\alpha$-D-glucopyranoside and Methyl 2,3,4Tris-O-\{N-[2,3-di-(hydroxyl)-benzoyl]-aminopropyl $\}-\alpha$-D-glucopyranoside Inorg. Chem. 2001, 40, 7079-7086.

19. Harris, W. R.; Carrano, C. J.; Cooper, S. R.; Sofen, S. R.; Avdeef, A. E.; McArdle, J. V.; Raymond, K. N. Coordination Chemistry of Microbial Iron Transport Compounds. 19. Stability Constants and Electrochemical Behavior of Ferric Enterobactin and Model Complexes. J. Am. Chem. Soc. 1979, 101, 6097-6104

20. Pecoraro, V. L.; Harris, W. R.; Wong, G. B.; Carrano, C. J.; Raymond K. N. Coordination Chemistry of Microbial Iron Transport Compounds. 23. Fourier Transform Infrared Spectroscopy of Ferric Catecholamide Analogues of Enterobactin. J. Am. Chem. Soc. 1983, 105, 4623-4633.

21. Scarrow, R. C.; Ecker, D. J.; Ng, C.; Liu, S.; Raymond, K. N. Iron(III) Coordination Chemistry of Linear Dihydroxyserine Compounds Derived from Enterobactin. Inorg. Chem. 1991, 30, 900-906.

22. Bluhm, M. E.; Hay, B. P.; Kim, S. S.; Dertz, E. A.; Raymond, K. N. Corynebactin and a Serine Trilactone Based Analogue: Chirality and Molecular Modeling of Ferric Complexes. Inorg. Chem. 2002, 41, 54755478.

23. Isied, S. S.; Kuo, G.; Raymond, K. N. Coordination Isomers of Biological Iron Transport Compounds. V. The Preparation and Chirality of the Chromium (III) Enterobactin Complex and Model Tris(catechol)chromium(III) Analogues. J. Am. Chem. Soc. 1976, 98, 1763-1767.

24. Neilands, J. B.; Erickson, T. J.; Rastetter. W. H. Stereospecificity of the Ferric Enterobactin Receptor of Escherichia coli K-12. I Biol. Chem. 1981, 256, 3831-3832

25. Colton, R.; D'Agostino, A.; Traeger, J. C. Electrospray Mass Spectrometry Applied to Inorganic and Organometallic Chemistry. Mass Spectrom. Rev. 1995, 14, 79-106.

26. Beck, J. L.; Colgrave, M. L.; Ralph S. F.; Sheil, M. M. Electrospray Ionization Mass Spectrometry of Oligonucleotide Complexes with Drugs, Metals, and Proteins. Mass Spectrom. Rev. 2001, 20, 61-87.

27. Gledhill, M. Electrospray Ionization-Mass Spectrometry of Hydroxamate Siderophores. Analyst 2001, 126, 1359-1362.

28. Spasojevic, I.; Boukhalfa, H.; Stevens, R. D.; Crumbliss, A. L. Aqueous Solution Speciation of Fe(III) Complexes with Dihydroxamate Siderophores Alcaligin and Rhodotorulic Acid and Synthetic Analogues Using Electrospray Ionization Mass Spectrometry. Inorg. Chem. 2001, 40, 49-58.

29. Berner, I.; Greiner, M.; Metzger, J.; Jung, G.; Winkelmann, G. Identification of Enterobactin and Linear Dihydroxybenzoylserine Compounds by HPLC and Ion Spray Mass Spectrometry (LC/MS and MS/MS). Biol. Metals 1991, 4, 113-118.

30. Kilz, S. Lenz, C. Fuchs, R. Budzikiewicz, H. A Fast Screening Method for the Identification of Siderophores from Fluorescent Pseudomonas spp. by Liquid Chromatography/Electrospray Mass Spectrometry. J. Mass Spectrom. 1999, 34, 281-290.

31. McCormack, P.; Worsfold, P. J.; Gledhill, M. Separation and Detection of Siderophores Produced by Marine Bacterioplankton Using High- 
Performance Liquid Chromatography with Electrospray Ionization Mass Spectrometry. Anal. Chem. 2003, 75, 2647-2652.

32. Gledhill, M.; McCormack, P.; Ussher, S.; Achterberg, E. P.; Mantoura, R. F. C.; Worsfold, P. J. Production of Siderophore Type Chelates by Mixed Bacterioplankton Populations in Nutrient Enriched Seawater Incubations. $>$ Mar. Chem. 2004, 88, 75-83.

33. Hayen, H.; Volmer, D. A. Different Iron-Chelating Properties of Pyochelin Diastereoisomers Revealed by LC/MS. Anal. Bioanal. Chem. 2006, $385,606-611$

34. Corey, E. J.; Bhattacharyya, S. Total Synthesis of Enterobactin, a Macrocyclic Iron Transporting Agent of Bacteria. Tetrahedron Lett. 1977, $45,3919-3922$.

35. Fridgen, T. D.; MacAleese, L.; McMahon, T. B.; Lemaire, J.; Maitre, P. Gas Phase Infrared Multi-Photon Dissociation Spectra of Methanol, Ethanol, and Propanol Proton-Bound Dimers, Protonated Propanol, and the Propanol/Water Proton-Bound Dimer. Phys. Chem. Chem. Phys. 2006, 8, 955-966.

36. Little, D. P.; Speir, J. P.; Senko, M. W.; O'Connor, P. B.; McLafferty, F. W. Infrared Multiphoton Dissociation of Large Multiply Charged Ions for Biomolecule Sequencing. Anal. Chem. 1994, 66, 2809-2815.

37. Zhang, J.; Schubothe, K.; Li, B.; Russell, S.; Lebrilla, C. B. Infrared Multiphoton Dissociation of O-Linked Mucin-Type Oligosaccharides. Anal. Chem. 2005, 77, 208-214.

38. Dunbar, R. C. Kinetics of Low-Intensity Infrared Laser Photodissociation. The Thermal Model and Application of the Tolman Theorem. J. Chem. Phys. 1991, 95, 2537-2548.

39. Uechi, G. T.; Dunbar, R. C. The Kinetics of Infrared Laser Photodissociation of $n$-Butylbenzene Ions at Low Pressure. J. Chem. Phys. 1992, 96, 8897-8905.

40. Freitas, M. A.; Hendrickson, C. L.; Marshall, A. G. Gas Phase Activation Energy for Unimolecular Dissociation of Biomolecular Ions Determined by Focused Radiation for Gaseous Multiphoton Energy Transfer (FRAGMENT). Rapid Commun. Mass Spectrom. 1999, 13, 1639-1642.

41. Freitas, M. A.; Hendrickson, C. L.; Marshall, A. G. Determination of Relative Ordering of Activation Energies for Gas Phase Ion Unimolecular Dissociation by Infrared Radiation for Gaseous Multiphoton Energy Transfer. J. Am. Chem. Soc. 2000, 122, 7768-7775.

42. Senko, M. W.; Canterbury, J. D.; Guan, S.; Marshall, A. G. A HighPerformance Modular Data System for Fourier Transform Ion Cyclotron Resonance Mass Spectrometry. Rapid Commun. Mass Spectrom. 1996, 10 1839-1844.

43. Karpishin, T. B.; Raymond, K. N. The First Structural Characterization of Metal-Enterobactin Complex: [V(enterobactin) $]^{2-}$. Angew. Chem. Int. Ed. Engl. 1992, 31, 466-468.

44. Brickman, T. J : McIntosh, M. A Overexpression and Purification of Ferric Enterobactin Esterase from Escherichia coli. J. Biol. Chem. 1992, 267 $12350-12355$

45. Thölmann, D.; Tonner, D. S.; McMahon, T. B. Spontaneous Unimolecular Dissociation of Small Cluster Ions, $\left(\mathrm{H}_{3} \mathrm{O}^{+}\right) \mathrm{L}_{n}$ and $\mathrm{Cl}^{-}\left(\mathrm{H}_{2} \mathrm{O}\right)_{n}(n=$ 2-4), under Fourier Transform Ion Cyclotron Resonance Conditions. J. Phys. Chem. 1994, 98, 2002-2004.

46. Price, W. D.; Schnier, P. D.; Jockusch, R. A.; Strittmatter, E. F.; Williams, E. R. Unimolecular Reaction Kinetics in the High-Pressure Limit Without Collisions. J. Am. Chem. Soc. 1996, 118, 10640-10644.

47. Dunbar, R. C. BIRD (Blackbody Infrared Radiative Dissociation): Evolution, Principle, and Applications. Mass Spectrom. Rev. 2004, 23, 127 158.

48. Hannis, J. C.; Muddiman, D. C. Tailoring the Gas-Phase Dissociation and Determining the Relative Energy of Activation for Dissociation of 7-Deaza Purine Modified Oligonucleotides Containing a Repeating Motif. Int. J. Mass Spectrom. 2002, 219, 139-150. 